\title{
PEACEFUL CO-EXISTENCE BETWEEN CHIMPANZEE AND MAN IN WEST AFRICA
}

\author{
by \\ SINCLAIR DUNNETT, JO VAN ORSHOVEN \& HELMUT ALBRECHT \\ Institute of Taxonomic Zoology, Department of Animal Behaviour, University of Amsterdam, \\ The Netherlands
}

\begin{abstract}
RESUME
Pendant une mission d'étude de l'Université d'Amsterdam sur le comportement des chimpanzés à l'état sauvage (République de Guinée, province de Kindia) les auteurs se sont intéressés également aux relations entre ces anthropoïdes et les êtres humains. La population humaine se montre très tolérante et plutôt indifférente envers les chimpanzés malgré que ces derniers peuvent faire des dégats à leurs produits agricoles. De ce point de vue l'avenir des chimpanzés est assuré dans cette province de la République de Guinée à la condition que les autres facteurs qui peuvent nuire à la presence de chimpanzés ne changeraient pas.
\end{abstract}

During the winter of $1968 / 69$, the authors of this paper were members of the International Chimpanzee Expedition working in the Republic of Guinea. They are pleased to report that although no large continuous areas have been set aside for the exclusive protection of the chimpanzee, Pan troglodytes (Blumenbach, 1779), nevertheless man and chimpanzee seem to have come to some sort of mutual adjustment in many areas, and that consequently chimpanzees in Guinea are not in imminent danger of extermination if the status quo is maintained.

The primary commission of the International Chimpanzee Expedition was to film and record details of the behaviour of chimpanzees living in their natural environment. Detailed accounts of the behaviour observed are to be published in other papers; the present brief paper will confine itself mainly to describing, for one particular area, the features which make co-existence between chimpanzee and man possible. The implications this may have for the chimpanzees will be considered, and brief comparisons made with chimpanzee-human relationships in some other parts of Africa.

The authors studied chimpanzees in two areas in Guinea, one population at Bossou (near N'Zérékoré) in the southern part of the country, and the other at Sougueta in the western part. The latter population is the subject of the present paper. During their study of it the authors were based at a citrus-fruit plantation called Kanka Sili. This plantation is about $50 \mathrm{~km}$ east of the area near Kindia where Henry Nissen made his pioneering study of chimpanzee behaviour in 1930 .

A sketch-map of Kanka Sili and its environs is shown in fig. 1. The plantation, which consisted mainly of bergamot and grapefruit trees, was bordered on its south and west sides by secondary forest with thick undergrowth. The eastern boundary of the larger part of the plantation was formed by the river $\mathrm{A}$, whose banks were covered with gallery forest on either side, generally to a distance of 5-15 m, but locally even up to $200 \mathrm{~m}$. The banks of the rivers $\mathrm{B}$ and $\mathrm{C}$ were similarly covered. The smaller part of the plantation to the north was bordered on its north side by elephant grass. The open plain to the north of this area was dotted with tall, straight borassus palms, and merged through impenetrable (for men) elephant grass in its northern part to forest along the base of the cliff shown. The chimpanzees ranged through all the wooded part of the area by the routes shown, and also entered the plantation to take grapefruit. They crossed the plantation at times, but their exact paths there were not known. When moving along the paths in the gallery forests they would often vocalize loudly, making it easy to locate them.

The area shown on the map, although probably not the limit of the chimpanzees' range, was, however, the limit to which we followed the chimpanzees. (They probably also ascended the river $B$ from (2) and descended the river $A B C$ from (4), 
at least for several kilometres). Intensive observation of the chimpanzees was performed from hides, especially the one marked on the map. (The clearing beside which this hide was built was provisioned regularly with grapefruit to lure the chimpanzees to the spot.) However, we also followed the movements of the chimpanzees when they failed to come to any of our routine observation spots, and thus learnt some of the routes they regularly used. These are shown on the map. The chimpanzees were nomadic in that most of the population moved, in various groupings, at least one kilometre each day; however some, or maybe all, of the chimpanzees would sometimes stay within the area shown on the map (i.e. $5 \mathrm{~km}^{2}$ ) for several weeks on end. Typical movements over a period of two days might be as follows: some chimpanzees slept one night at (1), fed there for a short time in the morning, and then moved north through some lightly-wooded country to the top of the cliff (2) where they remained the rest of the day, and slept that night. The next morning they fed for an hour, at both the top and the base of the cliff, before splitting into two groups, one of which descended the river $B$, while the other returned along its route of the previous day, past its former feeding place (1) to the observation field (OF) where we observed them for several hours. They left in the afternoon and moved south to (3), where they slept for the night.

A consideration of other areas where chimpanzees have been intensively studied is relevant at this point. Two such areas are the Gombe Stream Game Reserve, Tanzania, and the Budongo Forest, Uganda. The former area is the site of the prolonged and continuing study by van Lawick-Goodall and her co-workers (see van Lawick-Goodall, 1968). The chimpanzees of the Budongo Forest have been studied by, i.a., Reynolds \& Reynolds (1965) and Sugiyama (1968).

The Gombe Stream Reserve appears from the descriptions of van Lawick-Goodall (1968) and Albrecht (unpub.) to be effectively an "island" in the bush containing populations of various wild animals which have little contact with human beings. A few fisherman live on that edge of the reserve which borders Lake Tanganyika, but they do not usually penetrate deep into the reserve. Nevertheless, the chimpanzees appeared to have a great fear of man before the research programme began; van Lawick-Goodall (1968) reports that initially the chimpanzees would flee when they saw her as far away as $500 \mathrm{yds}$., and that it took eight months before she could approach to $50 \mathrm{yds}$. from them.

In the Budongo Forest a somewhat different situation prevails. From the descriptions in Reynolds \& Reynolds, 1965, and Sugiyama, 1968, Budongo appears to be a large, near-continuous stretch of thick forest with a high population density of chimpanzees. The vegetation thus differs from the Gombe Stream area, where thick gallery forests merge through more open woodland on higher slopes to completely open ground on some of the peaks and ridges. Furthermore, in Budongo a number of people live in villages beside tracks through the forest, and it appears that numerous paths traverse the forest. Nevertheless the total area utilized regularly by man appears to be small, apart perhaps from timber operations. Reynolds \& Reynolds (1965) observed that the Budongo chimpanzees were not alarmed by people who approached as close as $30 \mathrm{~m}$ if these people were walking along their normal paths in the forest; however, these same chimpanzees became suspicious and fled if humans left the paths and entered the forest. Sugiyama (1968) reports that "... the people neither kill chimpanzees nor have much interest in them". Neither Reynolds \& Reynolds nor Sugiyama state whether chimpanzees raid crops; in view of the preceding statement one presumes they do not to any great extent.

The Gombe Stream Reserve and Budongo Forest are, then, two areas where the chimpanzee's future seems assured, not only owing to the legal protection existing in each area but also owing to the circumstances prevailing: namely, isolation in the one instance, indifference to chimpanzees of the few people living near them in the other.

From the map (fig. 1) and the description of the area given earlier in the paper it can be seen that the Kanka Sili population of chimpanzees lives in what is essentially a fine network of forests and small patches of forests between which lie large areas of open ground, most of which are utilized in a variety of ways by man. This contrasts strongly with the situation prevailing at the Gombe Stream Reserve and the Budongo Forest, where the chimpanzees occupy large continuous tracts of land. The observations we made while at Kanka Sili show that the chimpanzees' wanderings frequently brought them along those parts of paths which passed only a few hundred metres, or less, from villages. Details of some of these movements have been given earlier in this paper. In one respect, Kanka Sili resembles the Budongo Forest; 


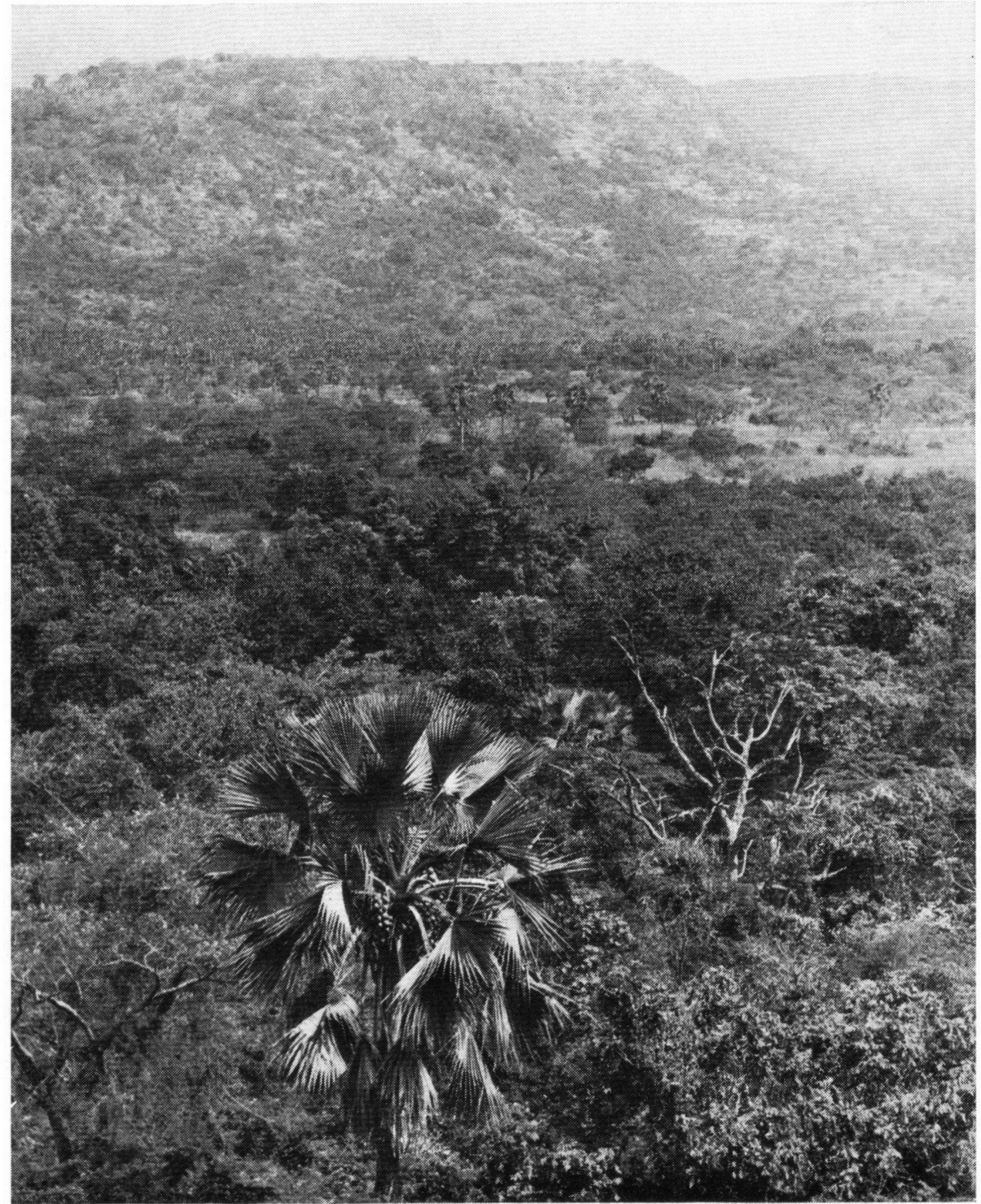

Plate 1. General view of part of the Kanka Sili area. This picture was taken from the "high tree" marked on the sketch-map (see fig. 1), looking approximately north-east. In the foreground may be seen the lush gallery forest of river A, particularly extensive at this point; behind that, and to the right, is the extreme northerly corner of the plantation; and beyond that lies the "open plain.... dotted with tall, straight borassus palms" described in the text. In the immediate foreground the crown of one of these palms is seen in detail; in the background, behind the last clearly visible palms, may be seen the gallery forest of river $B$. 


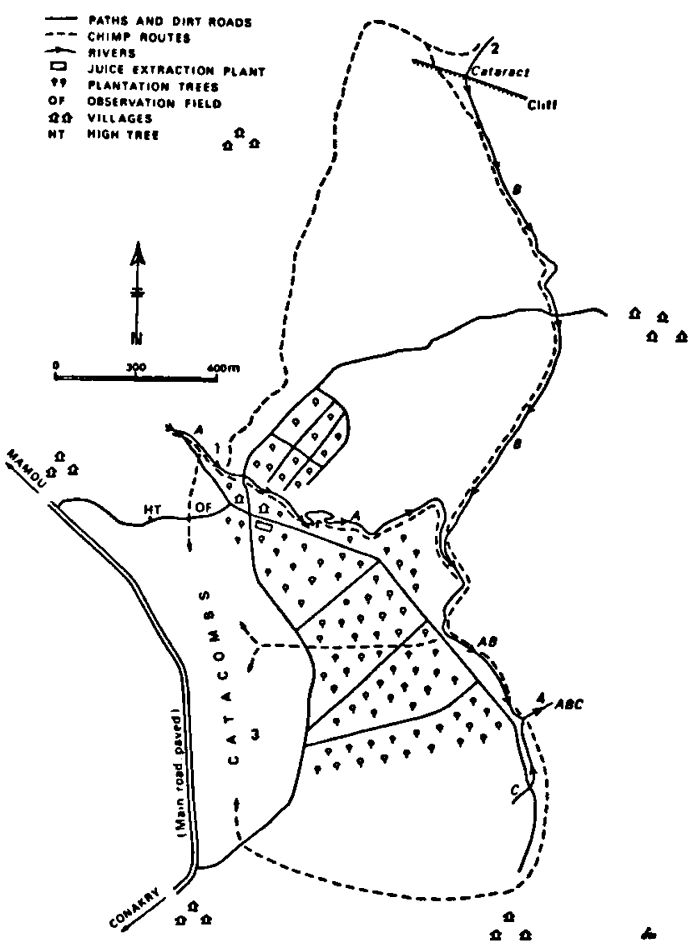

Fig. 1. Sketch-map of Kanka Sili and its environs, showing the extent of the commercial plantation and the principal human and chimpanzee routes. Most of the villages marked had some fields nearby with local staple crops such as rice or millet.

namely, chimpanzee paths cross human paths at many points, as may be seen for Kanka Sili from the map. Several times, the authors watched from concealment while a chimpanzee was about to cross a road along which people were walking. The chimpanzee would partially emerge on to the road, and immediately return to cover when it saw the people. However, the people might not be even out of sight before the chimpanzee would re-emerge, cross the road, and continue on its way.

The special condition of the Kanka Sili chimpanzees raises certain questions concerning their continued existence. Two occurrences could bring about rapid extermination of the population: firstly, habitat destruction; or secondly, wholesale shooting or trapping of the chimpanzees.

Habitat destruction, or at least further habitat destruction, does not seem likely to happen in this region. The area of the network occupied by the chimpanzees is already small in relation to the area of the region as a whole. Furthermore, the gallery forests are protected by law up to five metres on each side of the rivers. Many of the other patches of forest remaining are undesirable for agriculture, such as the "Catacombs", which are on a slope, or the area at the top of the cliff, which is difficult of access.

Direct shooting of the chimpanzees is more likely to cause their extermination. In the past, killing them has been forbidden by both civil law and religious custom, and the general persistence of these observances today is well demonstrated by the remarkable lack of shyness of the chimpanzees towards man. Even in the early part of our study we could approach to within $120 \mathrm{~m}$ of them, and within a month or so it was possible to approach to within $40 \mathrm{~m}$, provided we did not show undue interest in what they were doing. They were even less shy of the local inhabitants than of the authors; the reactions of chimpanzees to people crossing their path has already been described. Furthermore several chimpanzees were once seen to remain indifferent to a plantation worker who was noisily shaking a tree, to make fall its fruit, only $20 \mathrm{~m}$ from them. These examples seem to indicate that the chimpanzees can discriminate to some extent between individual persons, or possibly between persons in certain types of situations.

Nevertheless, chimpanzees are shot in Guinea from time to time. We heard various stories to this effect, and shortly after our arrival at Kanka Sili we saw it for ourselves when a man carrying a rifle tried to sell us an infant chimpanzee which he had certainly acquired by shooting the mother. Chimpanzees are still legally protected in Guinea except when they raid crops, and it is this point which must give cause for concern. Even countries with fairly extensive game control and law enforcement divisions often find it difficult to determine if claims of crop damage are genuine, when the marauding animal has already been shot by the farmer making the claim. Guinea does not have a large game department, but fortunately the local authorities are very willing to prosecute flagrant violations.

The chimpanzees at Kanka Sili raided both the small subsistence-level farms and the commercial plantation. From the subsistence farms rice and millet were taken. We gathered from conversations with the farmers that they did occasionally shoot a chimpanzee found raiding their crops, but nevertheless they do not make a policy of shooting chimpanzees on sight, as is done, for example, with antelope. Comparing our own observations with those of the Sixth Netherlands Chimpanzee Expedition, which studied this population two 


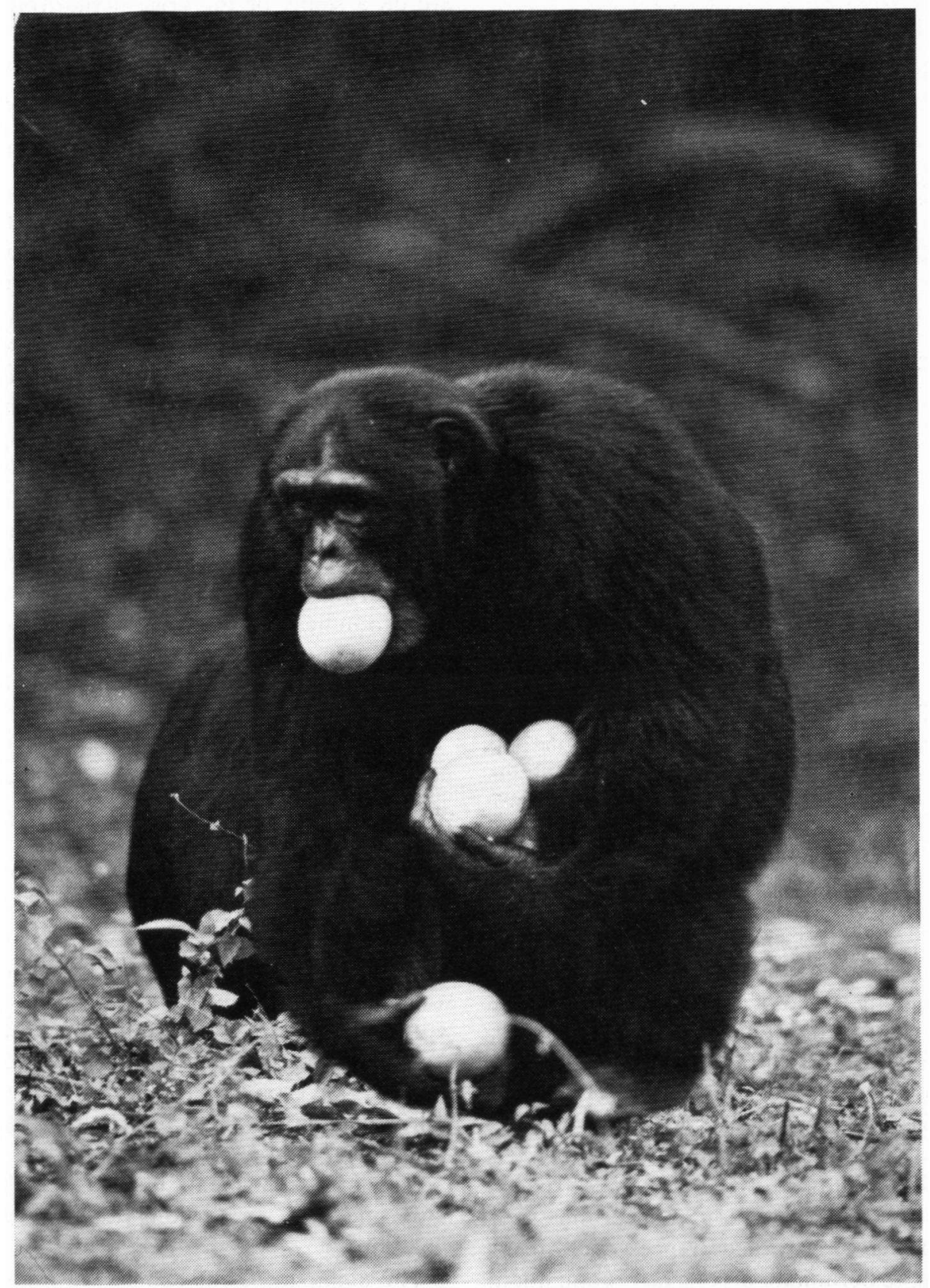

Plate 2. Bianchi, an adult male chimpanzee, leaves the observation field with an armful of grapefruit. Such a chimpanzee might consume daily 5 to 10 times this quantity. 
years prior to us, we can see that the population has remained stable at about fifty individuals (van Orshoven, unpub.), and this supports the view that generally the chimpanzees are not molested by the small farmers.

Of more cause for concern in the matter of chimpanzee survival is the raiding done on the commercial plantations. In this instance, much depends on the attitudes of plantation managers. The chimpanzees living in the vicinity of Kanka Sili used to enter the plantation regularly (though not daily) during the grapefruit ripening season and eat large quantities of grapefruit - probably at least 200 lbs. a day, judging by the quantities they used to consume at the provisioned observation field. The plantation manager however did not regard the chimpanzees as a serious pest, for two reasons: firstly, he considered the damage done to the trees by chimpanzees to be slight in comparison to that done by the baboons; and secondly, the bulky grapefruit crop was considered less valuable than the bergamot crop, from which a concentrated essence is extracted and a large return obtained for a small weight exported. Thus the manager did not molest the chimpanzees, although he was legally entitled to do so. It is easy to see however that this situation is in a rather delicate balance; a change in the value of the grapefruit, caused for example by increased local demand in an already existing grapefruit juice market, could alter the present tolerance towards the chimpanzees; or another manager making a different estimate of the damage done by the chimpanzees might decide that the population should be shot.

Kanka Sili is, then, an area where a moderately dense *) human population, practising both commercial and subsistence agriculture, co-exists with a community of chimpanzees. These chimpanzees live in a residual network of forests which also supports a number of other species of large

*) i.e. "dense" by African rural standards. mammals such as the yellow-backed duiker ( $\mathrm{Ce}$ phalophus silvicultor (Afzelius, 1815)), colobus monkey (Colobus polykomos (Zimmerman, 1780)), and bushbuck (Tragelaphus scriptus (Pallas, 1776)). Even if it were desirable, it would be impossible to turn the area as a whole into a national park, because of the large numbers of people living within it. As it now stands, the situation is a very happy one; in contrast, large wild mammals have already been eliminated from too many of the farming areas of Europe and Africa, and too many people accept that this is the way things should be. It is hoped that at Kanka Sili and other similar areas in Guinea the present balance between animal and man will be maintained; the very tameness which makes these chimpanzees so valuable for study would also make them very easy to destroy.

\section{ACKNOWLEDGEMENTS}

The field-work on which this paper is based, was carried out in the Republic of Guinea, and our thanks are due to the Guinean Government officials for their assistance and co-operation. Our thanks are also due to the embassy of the Federal Republic of Germany and to the staffs of Entreprise Guinéenne de Travaux Publics et Maritimes and of van Hattum and Blankevoort Ltd. for their assistance to us during our stay in Guinea. We further extend our thanks to Mr. P. Magnant, manager of the Kanka Sili plantation, to the German educational scheme at Kankan, particularly Mr. Seibold, and to Peter Fera, the cinematographer of Windrose-Dumont-Time.

Our thanks are due to the following organizations for financing the field-work: the 6571st Aeromedical Research Laboratory, Aerospace Medical Division; the Maatschappij voor Wetenschappelijk Onderzoek in de Tropen (Treub-Maatschappij); the Stiftung Volkswagenwerk; Windrose-Dumont-Time Filmproduktion, Hamburg; and WOTRO, the Netherlands Foundation for the Advancement of Tropical Research.

We wish to thank the University of Amsterdam for their support of the expedition, and also everybody in the Department of Animal Psychology and Ethology who helped in the preparations. Our thanks are particularly extended to Dr. Adriaan Kortlandt as instigator of the whole scheme, and also to Miss A. Pistoor and Messrs. W. Kerkhof and G. Nijk, for technical assistance.

\section{REFERENCES}

Lawick-Goodall, J. van, 1968. The behaviour of freeliving chimpanzees in the Gombe Stream Reserve. Animal Behav. Monogr., 1 : 161-312.

Reynolds, V. \& F. ReYNolds, 1965. Chimpanzees of the
Budongo Forest. In : I. DEVore, ed., Primate behavior. (Holt, Rinehart \& Winston, New York).

SugryamA, Y., 1968. Social organization of chimpanzees in the Budongo Forest, Uganda. Primates, 9: 225258. 